\title{
Differential responses of three sympatric seabirds to spatio-temporal variability in shared resources
}

\author{
Philippe S. Sabarros ${ }^{1}$, Joël M. Durant ${ }^{1}$, David Grémillet ${ }^{2,3}$, Robert J. M. Crawford $^{4,5}$, \\ Nils Chr. Stenseth ${ }^{1,6, *}$ \\ ${ }^{1}$ Centre for Ecological and Evolutionary Synthesis (CEES), Department of Biology, University of Oslo, PO Box 1066, \\ Blindern, 0316 Oslo, Norway \\ ${ }^{2}$ Centre National de la Recherche Scientifique, Centre d'Ecologie Fonctionnelle et Evolutive, 1919 route de Mende, \\ 34293 Montpellier, France \\ ${ }^{3}$ Percy FitzPatrick Institute, DST/NRF Centre of Excellence, and ${ }^{5}$ Animal Demography Unit, Department of Zoology, \\ University of Cape Town, Rondebosch 7701, South Africa \\ ${ }^{4}$ Ocean and Coasts, Department of Environmental Affairs, PO Box 52126, Cape Town 8001, South Africa \\ ${ }^{6}$ Institute of Marine Research, Flødevigen Marine Research Station, 4817 His, Norway
}

\begin{abstract}
Environmental change linked to climate and human activities may affect top predators via the food chain in marine systems. Understanding the functional link between resources and predator responses (e.g. foraging effort, reproductive success, population growth) is of crucial importance in the context of an ecosystem-based approach to fisheries. In the Benguela upwelling ecosystem located off the South African coast, both climate and overfishing may have modified the spatio-temporal availability of sardines and anchovies over the past 2 decades. These fish are prevalent prey items for 3 seabirds: the African penguin Spheniscus demersus, Cape gannet Morus capensis and Cape cormorant Phalacrocorax capensis. Species-specific responses of these 3 sympatric seabirds to the fluctuations in their shared prey are poorly understood. Here we used generalized additive modelling to examine the 'local population response' (i.e. number of breeders) of the 3 seabirds to spatio-temporal variations in prey availability from 1987 to 2007 . We showed that prey fluctuations influence seabird local population responses, presumably by modulating recruitment, breeding decision and breeding performance. We also identified speciesspecific population responses to prey availability: positive in African penguins and Cape gannets, and null in Cape cormorants. These patterns could be explained by seabirds partitioning prey in time via separated breeding periods, and space via accessing different foraging grounds due to specific feeding techniques. These responses also suggest different degrees of dependency upon pelagic resources among predators, which are likely due to contrasting foraging ecologies (e.g. dietary plasticity, foraging techniques, foraging ranges).
\end{abstract}

KEY WORDS: Population response - Prey fluctuations $\cdot$ Resource partitioning $\cdot$ Spheniscus demersus · Morus capensis · Phalacrocorax capensis · Benguela upwelling · South Africa

\section{INTRODUCTION}

Environmental changes linked to climate or human activities can affect the non-targeted top-predator community through the food web (Cury et al. 2008). Resource availability can affect the foraging effi- ciency, survival and reproductive output of top predators and can thereby drive their population dynamics (e.g. Croxall et al. 1999, Ainley et al. 2003). The response of predators (e.g. numerical response, functional response, reproductive success, net population growth) to prey variability is largely conditioned by 
species-specific characteristics that deal with morphology, behaviour and life-history traits. Fine ecological niche tuning may lead to morphological adjustments, which condition foraging techniques and diets (Abrams \& Griffiths 1981). It may also lead to adjustments of life-history traits such as the breeding phenology that enables the spatio-temporal match of predators and resource as well as competitor avoidance (Alley 1982). Within communities, species may show unique responses to the same perturbation (e.g. prey shortage). Few studies have looked into the mechanisms behind such responses within the higher trophic levels of marine ecosystems (e.g. Barrett \& Krasnov 1996, Croxall et al. 1999, Carscadden et al. 2002, Sandvik \& Erikstad 2008). This is unfortunate since climate change and overfishing in upwelling ecosystems are dramatically modifying the abundance and distribution of forage fish - a key component of these food webs - that notably exert bottom-up control on top predators (Bakun 1990, Cury et al. 2000). In the context of global changes affecting food webs and an ecosystem-based approach to fisheries, a need exists for a better understanding of the response of communities of non-targeted marine predators, particularly seabirds, to variable levels of prey availability (Cury et al. 2008, 2011).

The southern Benguela upwelling ecosystem located off the South African coast supports large quantities of small pelagic fish, mainly sardines Sardinops sagax and Cape anchovies Engraulis encrasicolus, which are heavily targeted by commercial purseseine fisheries. Over the past 2 decades (1987 to 2007) these prevalent forage fish, previously associated with the western coast of South Africa, have progressively shifted towards the east (van der Lingen et al. 2005, Fairweather et al. 2006). Environmental fluctuations linked to climate change (e.g. Roy et al. 2007) and spatially unbalanced fishing pressure (Coetzee et al. 2008) may have caused this major distributional shift. In addition, overall sardine biomass and catches that were at a low level in the early 1990s increased substantially (approximately 7 -fold) and reached a peak in 2004 (van der Lingen et al. 2005, Fairweather et al. 2006). Sardines and anchovies are predominant prey items for 3 seabird species breeding in South Africa: the African penguin Spheniscus demersus (68 to $96 \%$ by mass of total diet; Crawford \& Dyer 1995), the Cape gannet Morus capensis (62 to $85 \%$; see references in Hockey et al. 2005) and the Cape cormorant Phalacrocorax capensis (49 to $100 \%$; Crawford \& Dyer 1995). Therefore, such forage fish variability (i.e. distributional shifts and abundance fluctuations) provides a context for studying potentially induced responses in seabird populations that are highly dependent on this resource.

Breeding populations of Cape gannets and Cape cormorants decreased in the westernmost South African colonies $(-35 \%$ for gannets, $-91 \%$ for cormorants) throughout the period between 1987 and 2007, while increasing in the easternmost colonies (+100\% for gannets, $+14 \%$ for cormorants), suggesting that both species followed the prey shift eastward (Crawford et al. 2008). African penguins exhibited the opposite pattern $(+190 \%$ in the west and $-70 \%$ in the east). Crawford et al. (2008) suggested that penguins relied on the few anchovies that remained available on the western coast throughout the period, compared to sardines. In order to understand such regional varying patterns in the number of breeding birds, it is necessary to investigate the response of the seabirds to prey fluctuations in terms of breeding numbers at each colony (called hereafter 'local population response') and to consider the species-specific characteristics so as to explain the observed patterns (e.g. Sandvik \& Erikstad 2008). The 3 studied seabird species are characterised by differences in timing of the breeding season and in morphological characteristics that imply particular modes of locomotion (e.g. swimming, flapping flight, gliding flight), foraging techniques (e.g. pursuit-diving at surface and intermediate depths, plunge-diving at the surface) and foraging ranges (from 40 up to $240 \mathrm{~km}$, depending on species). Few multi-species studies have investigated and compared the nature of the differential species responses in the light of their particular characteristics and adaptations (e.g. Furness \& Barrett 1991, Barrett \& Krasnov 1996, Carscadden et al. 2002, Sandvik \& Erikstad 2008).

In colonial species, vital rates (e.g. reproductive success, survival) and meta-population processes (e.g. inter-patch migrations of certain age-classes) drive population dynamics (Boulinier \& Lemel 1996, Hanski \& Gaggiotti 2004). Food availability influences seabird population dynamics through changes in breeding success, i.e. the number of chicks successfully raised by the end of the breeding season (e.g. Barrett \& Krasnov 1996, Durant et al. 2003, Crawford et al. 2006a, Lewis et al. 2006, Le Bohec et al. 2008, Durant et al. 2010), survival of immature birds and adults (e.g. Crawford et al. 2008, Le Bohec et al. 2008), and mature birds' decisions whether to breed depending on their body condition (e.g. Danchin \& Cam 2002, Vleck \& Vleck 2002). Metapopulation processes may also depend on food availability, such as the immigration of first-time breeders 
to non-natal colonies (e.g. Crawford 1998, Dittmann et al. 2005).

In this study we examine the numbers of breeding pairs of 3 seabirds of the southern Benguela ecosystem, the African penguin, the Cape gannet and the Cape cormorant, at different colonies during their respective peak breeding seasons (i.e. 'local population response') in relation to spatio-temporal variability of sardines and anchovies over a $20 \mathrm{yr}$ period (1987 to 2007). Our underlying hypothesis is that prey abundance and distribution control the proportion of potential breeders that eventually and successfully breed in a given year in a particular colony. We assume that food availability prior to peak breeding time (middle of the breeding period) controls the 'local population response' (see details in 'Materials and methods'). Here we test (1) whether prey availability prior to and in the early part of the breeding season regulates the 'local population response' of the 3 seabirds and (2) whether these seabirds exhibit comparable responses to fluctuations of availability of their shared prey with regard to the recent spatial shift of these pelagic forage fish.

\section{MATERIALS AND METHODS}

\section{Seabird ecology}

The ecology of the 3 seabird species differs in several aspects. African penguins Spheniscus demersus are obligate swimmers and pursue prey in surface and intermediate layers down to $100 \mathrm{~m}$, usually within $80 \mathrm{~km}$ of their breeding colony. Cape gannets Morus capensis are plunge-divers and perform costefficient flights (gliding-flight) that allow them to cover large areas; they forage up to $240 \mathrm{~km}$ from their colony. Cape cormorants Phalacrocorax capensis can both swim and fly; they perform a 'flapping-flight' to reach foraging areas up to $40 \mathrm{~km}$ from the colony and then pursue prey underwater like African penguins (references in Hockey et al. 2005). The timing of the breeding season in South Africa also differs between seabird species: African penguins breed between February and October, while Cape gannets and Cape cormorants breed between September and March (Fig. 1a).

\section{Seabird monitoring}

The colonies of African penguins, Cape gannets and Cape cormorants breeding in the Western and
Eastern Cape provinces of South Africa (Fig. 1b) have been monitored during their respective breeding seasons since 1987 or earlier (see Underhill et al. 2006, Crawford et al. 2007a,b). The breeding localities of African penguins were visited several times during their main breeding season from February to October (Hockey et al. 2005), and ground counts of active nests were made; active nests were defined as paired birds defending a site, sites showing evidence of recent nest construction and sites with eggs or chicks (Crawford et al. 1990). Nest turnover was assumed to be constant across years, and the highest count of active nests in each year was assumed to represent the breeding population size (Underhill et al. 2006). At Cape gannet colonies, aerial photographs were taken between November and December, when most individuals are incubating or brooding (Crawford et al. 2007a). The numbers of breeding pairs of Cape gannets were estimated from measurements of the area occupied by breeding birds on aerial photographs (ground-truthed) combined with nest density measures (Crawford et al. 2007a). Ground counts of active nests were taken repeatedly at Cape cormorant colonies (as we did for African penguins) throughout the main breeding season from September to February (Hockey et al. 2005). The highest count of active nests defined the yearly breeding population (Crawford et al. 2007b).

In this study, we used the numbers of breeding pairs of African penguins available between 1987 and 2007, Cape gannets between 1987/1988 and 2005/2006 and Cape cormorants between 1987/1988 and 2006/2007. We considered 17 African penguin colonies, 3 Cape gannet colonies and 6 Cape cormorant colonies (see Fig. 1c,d and Section 1 of the supplement at www.int-res.com/articles/suppl/m468 p291_supp.pdf for details concerning colonies used).

\section{Prey abundance and distribution}

The availability of sardines and Cape anchovies was derived from spatially explicit fishing data reported by South African purse-seine fishermen (i.e. catch location, fish composition) and gathered by the Department of Agriculture, Forestry and Fisheries (Cape Town, South Africa) for the period between 1987 and 2007 (see Section 2 in the supplement at www.int-res.com/articles/suppl/m468p291_supp.pdf). Despite the fact that fishing is not spatially uniform (see Fig. S2.1 in the supplement) catch data may be used to estimate fish abundance in this instance. 


\section{(a) Breeding seasons}

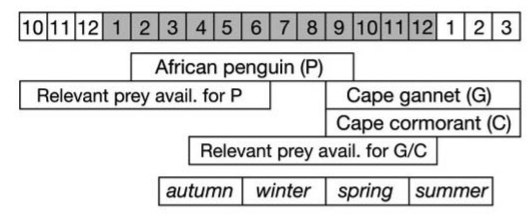

\section{(c) Breeding locations in Western Cape}

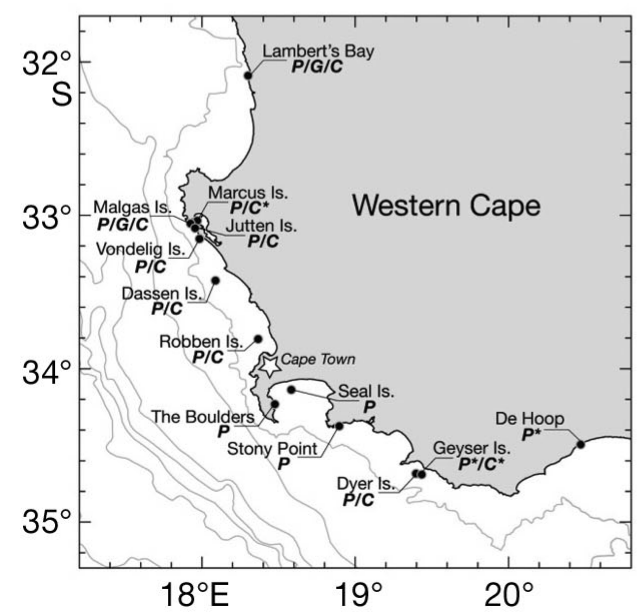

(b) Breeding regions in South Africa

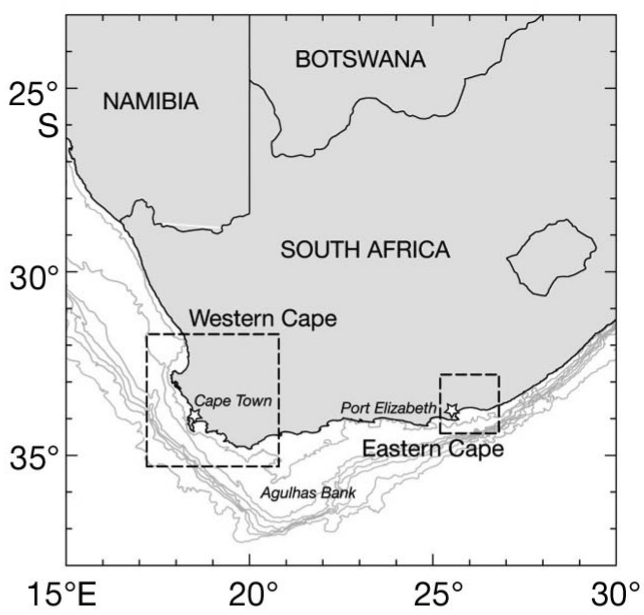

(d) Breeding locations in Eastern Cape

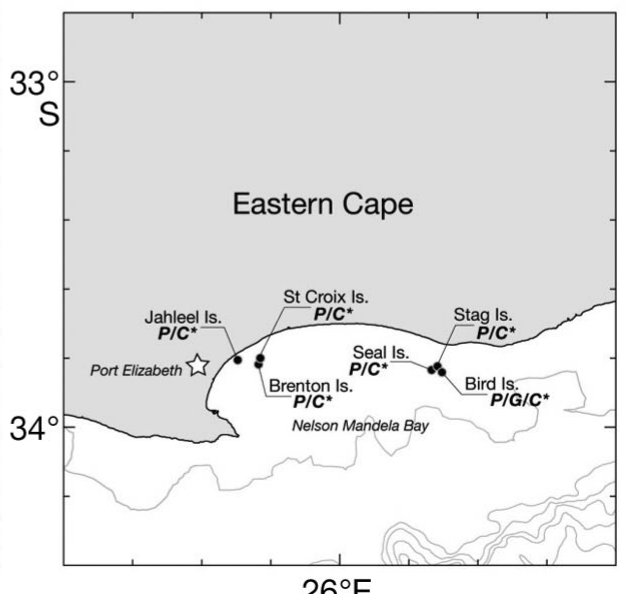

Fig. 1. (a) Breeding seasons of African penguins Spheniscus demersus, Cape gannets Morus capensis and Cape cormorants Phalacrocorax capensis, along with the respective relevant periods for prey (i.e. the months including the period prior to breeding and the early part of the reproductive season). (b) Breeding regions in South Africa with colonies located in (c) the Western Cape region and (d) the Eastern Cape region, indicating presence of African penguins $(\mathrm{P})$, Cape gannets (G) and Cape cormorants (C) at the respective localities. Asterisks: colonies excluded from the analysis for the respective seabird species (see details in Section 1 in the supplement at www.intres.com/articles/suppl/m468 p291_supp.pdf)
Assuming that forage fish catchability remained constant with fluctuations and that the estimation of fish abundance was increasingly accurate with sampling effort (i.e. number of fishing events), we computed an index of fish abundance as the average catch made within a defined area and period:

$$
\overline{\operatorname{Catch}}_{j, k}=\sum_{i} \operatorname{Catch}_{i, j, k} / N_{i, j, k}
$$

Hence, the average catch at $j$ and $k$ equals the sum of catch over sample size of fishing events for each fishing event. In the formula $i$ is the fishing event, $j$ is the area, $k$ is the period considered and $N$ is the number of fishing events. The use of this index of abundance (in t haul ${ }^{-1}$ sector $^{-1}$ period $^{-1}$ ) based on catch per effort data was validated against fisheryindependent hydroacoustic survey data that concurred in time and space for a limited number of years (see Fig. S2.2 in the supplement). In order to obtain the distribution of the pelagic prey along the coast, we first divided the South African coast into 20 sections of about $100 \mathrm{~km}$ width that extend offshore to the $500 \mathrm{~m}$ isobath (see Fig. S2.3 in the supplement). We then extracted all sardine and anchovy fishing events during the periods defined in relation to the seabirds' breeding cycles (see definition of these periods in the section 'Analysis' below; Fig. 1a), and we computed an abundance index for each coastal section. Finally, we combined the sardine and anchovy distributions in order to obtain the distribution of seabird pelagic prey along a NW-SE gradient. The prey distribution along the NW-SE gradient generally showed a mono- or bi-modal distribution. In the analysis we determined for each colony of each seabird species the magnitude and the distance of the nearest peak of abundance (PoA) to the colony in order to characterize the prey availability (see Fig. S2.4 in the supplement). 


\section{Nesting space}

All breeding sites were relatively flat areas (low elevation, no cliff). We estimated the total surface of the breeding localities (in $\mathrm{m}^{2}$ ) from polygons defined with Google Earth 4.2 (Version 2007, earth.google. com). Cape gannets nest on flat areas on islands. Nesting habitat can be more diversified for African penguins, e.g. in burrows, under brush, in scrapes on the surface of the ground. Cape cormorants often build their nests on rocks near the shoreline. Despite the 3 seabirds' use of diverse nesting grounds we assumed that their respective usable nesting space in colonies was proportional to the calculated surface areas. We used the surface area to compare the relative nesting space between breeding localities and eventually to account for these differences in the statistical model when appropriate (see 'Analysis' section below).

\section{Analysis}

We assumed that in African penguins, Cape gannets and Cape cormorants, the breeding decision of adult birds, the recruitment of juvenile birds to the pool of breeders (when juvenile birds breed for the first time) and the ability for breeders to avoid failure prior to peak breeding are the major processes controlling the number of active breeders at the peak breeding season each year at each of the colonies. The breeding decision of a mature bird (being a firsttime or experienced breeder) generally depends on body condition at the onset of breeding, which is linked to how successfully it has fed prior to the breeding season (Danchin \& Cam 2002, Vleck \& Vleck 2002). During the non-breeding period, African penguins, Cape gannets and Cape cormorants may move extensively away from their respective colonies though staying within South African and neighbouring countries' waters (e.g. Namibia; Hockey et al. 2005). Therefore, the distance to the PoA may not be as relevant as the magnitude of the PoA in that particular case. The recruitment of juveniles to the breeder pool at natal or non-natal colonies depends on the evaluation of local conditions at the colony by these young birds when the breeding season starts (Boulinier \& Lemel 1996, Dittmann et al. 2005). The ability for a pair of breeders to carry out the breeding enterprise is conditioned by the time they spend at the nest and the amount of food they are able to bring back to the chick, which are both dependent on the prey availability at sea (e.g. Lewis et al. 2006), notably, prior to the reproductive peak (i.e. during the first half of the breeding season) for pairs present at the time of the peak. During the early part of the breeding season, adults raising young chicks are particularly sensitive to prey availability since central-place foraging is strongly limited by the time they are able to leave the nest unattended. We therefore defined periods that encompass these determinant periods: a few months prior to and during the early part of the breeding season, when food availability is likely to control the breeding decision of adult birds, the recruitment of new breeders and the breeding success. These periods were April to December for gannets and cormorants and October to June for penguins (see Fig. 1a). In the 3 seabird species, we related the 'local population response' at the different localities to the yearly distribution of their prey along the coast, considered over the putatively relevant periods. We characterised prey availability by the magnitude and distance of the PoA instead the abundance within a foraging range. We considered that the realised foraging range of a predator directly depends on prey availability, i.e. a predator will explore a larger area if prey availability is reduced. Therefore, we considered that the magnitude and distance of the nearest PoA (respectively, Magn.PoA and Dist.PoA) was a better indicator than the abundance of prey within a fixed range, which does not take into account that the foraging area (and energy expenditure) may vary between years and that it generally increases with prey scarcity. We used generalised additive models (GAM) to account for the effects of the magnitude and distance of the peak of abundance to each colony on the 'local population response' (family: Poisson; link: identity). Specifically, the GAM models can be formulated as follows:

$$
Y_{t}=b+\mathrm{col}+f\left(\text { Magn.PoA }_{t}\right)+g\left(\text { Dist.PoA } A_{t}\right)+\varepsilon_{t}
$$

with $Y_{t}$ as the breeding pair number considered at time $t$. Nonparametric smoothing functions were represented by $f$ and $g$ that specified, respectively, the effect of prey abundance (Magn.PoA) and distance of the peak of fish abundance to each colony (Dist.PoA) on the breeding pair number $Y$. The intercept was $b$, and $\varepsilon$ was the noise term. The potential effect of the colony from which data were sampled was represented by the factor variable col. The GAM procedure automatically chose the degrees of freedom of the smoothing functions $f$ and $g$ (i.e. linearity of the curve) based on the generalised cross-validation (GCV) score (an estimated degree of freedom that equals 1 indicates a linear relationship). Statistical analysis was performed with R software 2.7.0 (R De- 
velopment Core Team 2007) using the gam function in the mgCV package (Wood 2006). To account for differences among colony population sizes within the GAM models, we included either the colony as a regular factor covariate or the index of nesting space as a continuous covariate. Model selection was performed by minimising the GCV score and maximising the $\mathrm{R}^{2}$ (Wood 2006). We found no autocorrelation in the residuals of the selected models using the acf function.

\section{RESULTS}

In this section we present the best model explaining the breeding population size selected by GCV for each of the 3 seabirds (see Fig. 1a). For a complete list of models tested see Section 3 in the supplement at www.int-res.com/articles/suppl/m468p291_supp.pdf.

The numbers of African penguins Spheniscus demersus at their 17 colonies were positively related to the magnitude of the nearest PoA of combined anchovies and sardines and negatively to the distance of the PoA (Table 1, Fig. 2a). The effect of the magnitude of the PoA was linear, and the effect of the distance of the PoA was quasi-linear (estimated degrees of freedom close to 1), with saturation at longer distances (Fig. 2a).

Cape gannet Morus capensis breeding numbers at their 3 colonies were positively related to the magnitude of the nearest PoA and negatively related to the distance to the PoA (Table 1, Fig. 2b). Both PoA indices had a linear effect on the number of breeders (Fig. 2b).

The magnitude and distance of the PoA did not significantly affect Cape cormorant Phalacrocorax capensis breeding numbers at their 6 colonies in the Western Cape Province (the only ones analysed; Table 1). However, both PoA indices were associated with the response variable in the final model selected by minimising the GCV score and maximising the $\mathrm{R}^{2}$, and there was a consistent negative relationship between the magnitude of the PoA and breeding numbers over all the models tested (see Section 3 in the supplement). Nevertheless, we will refer to the cormorants' response as a 'null' response.

\section{DISCUSSION}

\section{Population processes controlled by resource availability}

Worldwide, prey is a prevalent factor that influences intrinsic population processes as well as metapopulation processes in seabird populations (Boulinier \& Lemel 1996, Durant et al. 2009). In the Benguela upwelling system, the dominant pelagic prey species, sardine and anchovy, have been shown to affect breeding success (Crawford et al. 2006a) and adult survival (Crawford et al. 2008) of African penguins Spheniscus demersus and have also been suggested to affect the recruitment of first-time breeders (Crawford 1998). In this study, we found that the 'local population response' of African penguins and Cape gannets Morus capensis depended to a large extent on food availability prior to and during the early part of the breeding season (see Table 1). This result supports our assumption that food conditions experienced by birds prior to and during the early part of the reproductive season may control the proportion of potential breeders that will eventually show up and try to breed at the respective colonies in a given year. Potential breeders include mature birds that have already bred once and that are associated with a given colony (fidelity) and young birds (recruits) that are ready to breed for the first time at any colony. Our results stress the importance of investigating processes

Table 1. Statistics of the generalized additive models by seabird species. The response variable is the number of breeding pairs. Col: a factor for which colonies take different levels; Surf: proxy for nesting space; Magn.PoA and Dist.PoA: abundance and distance of the peak of fish abundance to each colony, respectively; $f$ and $g$ : smoothing term functions; N: total number of observations; $y$ : year. Levels of significance are defined as follows: ${ }^{* * *} p<0.0001,{ }^{* *} p<0.001,{ }^{*} p<0.05$, non-significant $\mathrm{p}$-values are also reported

\begin{tabular}{|c|c|c|c|c|c|c|}
\hline Species & & - Covariates & - & Adj. $\mathrm{R}^{2}$ & $\mathrm{~N}$ & Period for prey \\
\hline $\begin{array}{l}\text { African penguin } \\
\text { Spheniscus demersus }\end{array}$ & $\mathrm{Col}^{* * *}$ & $f(\text { Magn.PoA })^{*}$ & $g(\text { Dist.PoA })^{*}$ & 0.728 & 291 & $\operatorname{Oct}(y-1)-\operatorname{Jun}(y)$ \\
\hline $\begin{array}{l}\text { Cape gannet } \\
\text { Morus capensis }\end{array}$ & $\operatorname{Surf}^{* * *}$ & $f(\text { Magn.PoA })^{*}$ & $g(\text { Dist.PoA })^{* * *}$ & 0.735 & 48 & $\operatorname{Apr}(y)-\operatorname{Dec}(y)$ \\
\hline $\begin{array}{l}\text { Cape cormorant } \\
\text { Phalacrocorax capensis }\end{array}$ & $\mathrm{Col}^{* * *}$ & $f(\text { Magn } . \mathrm{PoA})^{\mathrm{p}}=0.12$ & $g(\text { Dist.PoA })^{p=0.6}$ & 0.397 & 136 & $\operatorname{Apr}(y)-\operatorname{Dec}(y)$ \\
\hline
\end{tabular}


(a) African penguin

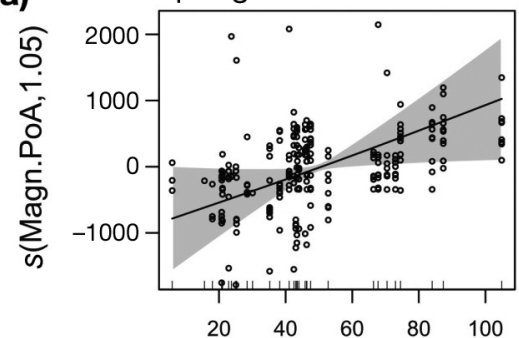

(b) Cape gannet

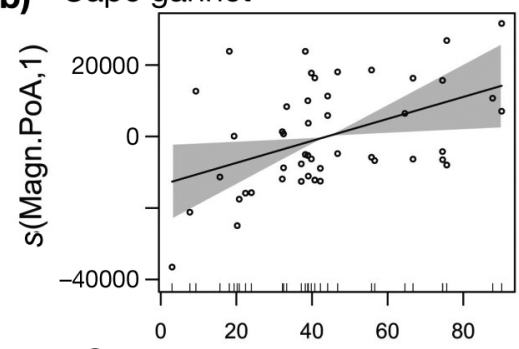

(c)

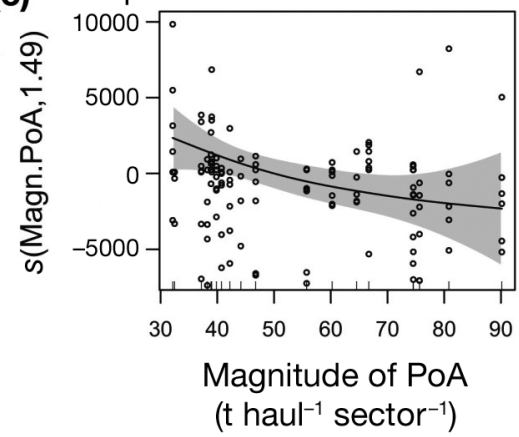

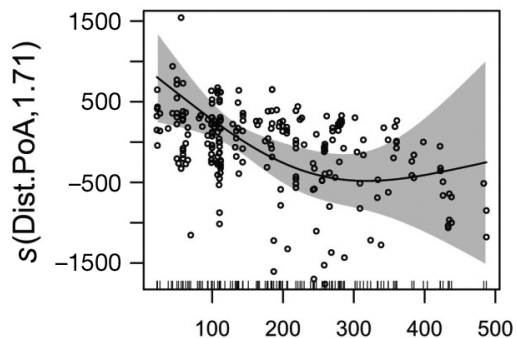
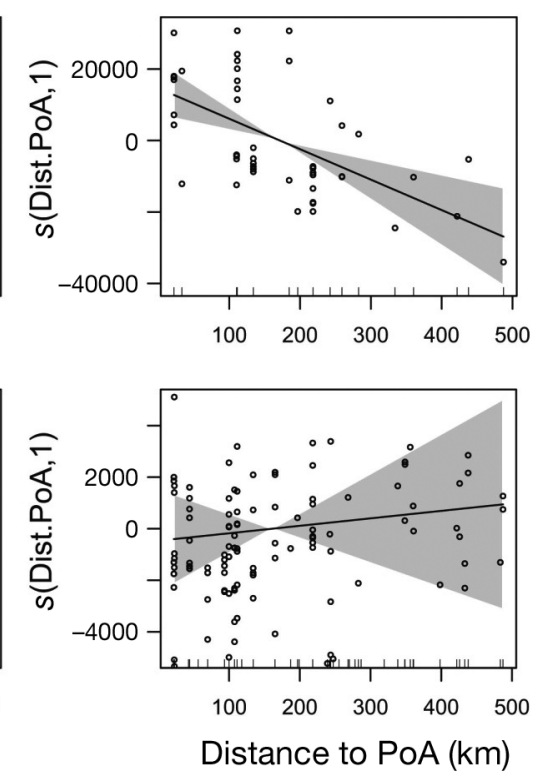

Fig. 2. Local breeding population responses of (a) African penguin Spheniscus demersus, (b) Cape gannet Morus capensis and (c) Cape cormorant Phalacrocorax capensis colonies to the magnitude of the nearest peak of abundance of prey ( $\mathrm{PoA}_{\text {; }}$ average catch in $\mathrm{t}_{\text {haul }}{ }^{-1}$ sector $^{-1}$ period $^{-1}$ ) and the distance to the PoA (in km). For the smoothing term $s(X, Y), X$ stands for the effect (Magn.PoA: magnitude of the PoA; Dist.PoA: distance to PoA) and $y$ is the estimated degrees of freedom of the smoothing term. Grey shading: approximate $95 \%$ confidence intervals of the smoothing terms

that, in addition to background population dynamics (e.g. breeding success, survival), likely play a major role in controlling the number of breeders. These other processes are (1) the bird's decision to breed, which depends on its body condition and eventually depends on the environmental conditions experienced between breeding seasons (e.g. Danchin \& Cam 2002); (2) the recruitment of first-time breeders to (potentially non-natal) colonies after young birds have evaluated suitability of local breeding conditions (Boulinier \& Lemel 1996, Crawford 1998); and (3) the ability of birds that have initiated breeding to avoid failure (Crawford et al. 2006a). These aspects of population and meta-population dynamics require further investigation through the use of dedicated models in conjunction with empirical data.

\section{Nature of local population responses}

The African penguin and Cape gannet exhibited positive responses to the variations in sardine and anchovy prey: increased abundance and proximity of these prey benefitted the 2 bird species, which adjusted their numbers accordingly at the different colonies (Fig. 2a,b). Such a direct response is typical of species with specialised diets and little ability or opportunity to switch to alternative prey (Croxall et al. 1999). Conversely, Cape cormorants Phalacrocorax capensis showed no significant response to the index of abundance of pelagic prey or the distance of colonies from peak prey concentrations (Fig. 1c), although these indices were contained in the best model (Table 1, see also Table S3.1 in the supplement at www.int-res.com/articles/suppl/m468 p291_supp.pdf). The absence of a strong pattern could be explained by (1) possible dietary plasticity of the Cape cormorant as described in other cormorants (e.g. Ainley et al. 1981, Grémillet et al. 1998, Kato et al. 2001) despite the fact that the Cape cormorant has been considered a pelagic-fish-specialist predator (Duffy 1989, Crawford \& Dyer 1995), or (2) extensive mortality from outbreaks of avian cholera that inflicted heavy mortality on Cape cormorants during the study period (Crawford et al. 1992, Waller \& Underhill 2007) and may have weakened any functional coupling between Cape cormorants and their prey.

\section{Partitioning the use of food resources}

Cape gannets and Cape cormorants breed at the same time of year (see Fig. 1a) and are therefore potential competitors for resources. We hypothesise that the contrasting responses of Cape gannets (positive) and Cape cormorants (null) to the variability of sardine and anchovy prey are related to the consequences of high versus low abundances of these pelagic fish on the vertical fish distribution in the 
water column (see Fig. 3 in Bakun \& Weeks 2004, Carscadden et al. 2002) and the ability of the 2 seabirds to exploit prey at different depths according to their hunting technique (Fig. 3). Indeed, when prey is abundant, the presence of large sub-surface predators (e.g. large predatory fish, pinnipeds, cetaceans) is supposedly enhanced. On the one hand, tunas and cetaceans present in this region may push fish shoals towards the surface making prey accessible to plunge-divers such as gannets (e.g. Evans 1982, Le Corre \& Jaquemet 2005). On the other hand, multi-species feeding associations may lead to increased inter-specific interference competition underwater (Camphuysen \& Webb 1999), from which cormorants may suffer, for instance with great white sharks Charcharodon carcharias which can attack birds (Johnson et al. 2006). To avoid this competition, we propose that Cape cormorants are able to switch from pelagic to benthic prey located in the vicinity of the colony (as suggested above). Comparable diet plasticity was observed in common murres Uria aalge off Labrador, whereby common murres found alternative benthic prey to cope with capelin scarcity (Carscadden et al. 2002). In the opposite situation, competition is reduced and fish tend to aggregate deeper when pelagic fish become scarce. Fish prey then become inaccessible to plunge-diving gannets, while still remaining accessible to cormorants that can capture prey at depth. Likewise, surface-feeding kittiwakes in the Barents Sea and off Newfoundland
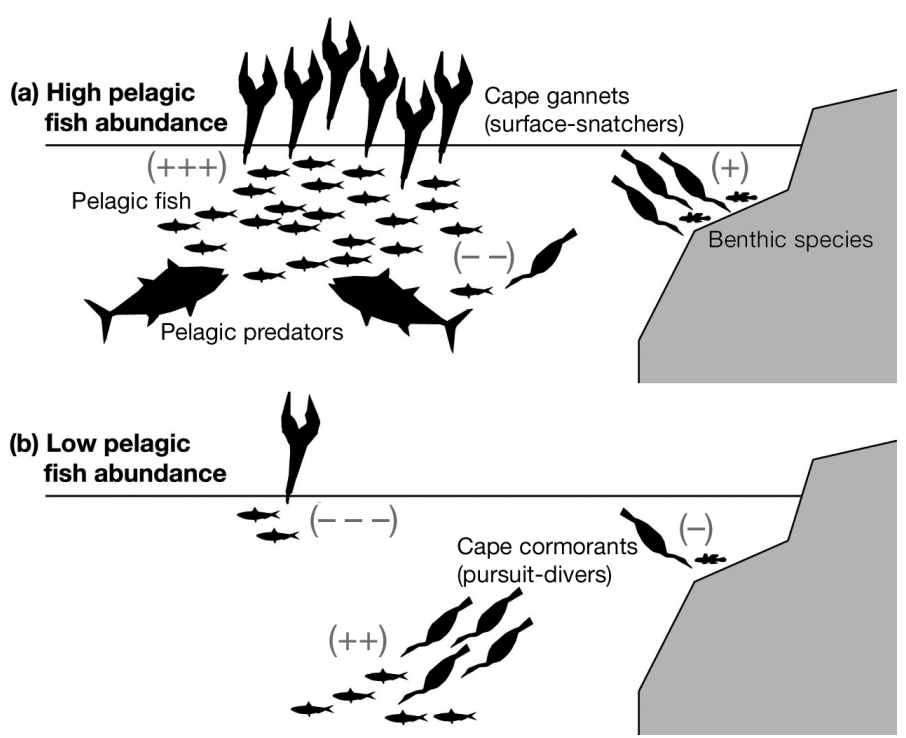

Fig. 3. Hypothetical situations for Cape gannets Morus capensis and Cape cormorants Phalacrocorax capensis in conditions of (a) high and (b) low pelagic fish abundance. Grey symbols: qualitative and quantitative numerical response of the seabirds in the alternative situations of low and high pelagic fish abundance suffered from capelin shortage, while pursuit-diving species fared better (Barrett \& Krasnov 1996, Carscadden et al. 2002). Moreover, Cape cormorants might be more successful when foraging in groups on modest prey resources, as seen in other Phalacrocorax species (e.g. Grémillet et al. 2004). By having contrasting abilities to exploit pelagic fish, gannets and cormorants may share resources through partitioning the use of vertical space. In turn, gannets and cormorants could be alternatively favoured depending on the abundance of sardines and anchovies because of their interaction (e.g. commensalism, interference) with other predators and differential accessibility to the prey items.

African penguins and Cape gannets breed at different times of the year (see Fig. 1a) and thereby forage at different periods of the annual migration route of anchovy and sardine off western South Africa. In spring, mature sardines and anchovies migrate towards spawning grounds located offshore (Crawford 1980; see Fig. 4a). In summer, the spawners return to coastal feeding grounds while eggs/larvae drift northwards into St Helena Bay's $\left(32.75^{\circ} \mathrm{S}\right.$, $18.02^{\circ} \mathrm{E}$ ) inshore nursery area (Crawford 1980; see Fig. 4b). In autumn, the young-of-the-year fish migrate southwards, and thus can be found along the southwest coast in autumn-winter (Crawford 1980; see Fig. $4 \mathrm{~b}$ ). Due to their respective modes of locomotion and thus different foraging ranges (see references in Hockey et al. 2005), gannets are more inclined to exploit spawning fish offshore in spring than are penguins. Moreover, such large aggregations of adult prey provide profitable feeding for gannets. Not surprisingly, the peak breeding season of gannets in November corresponds to the fish spawning season (Fig. 4a), whereas this is when penguins undertake their moult for which they stop feeding for $3 \mathrm{wk}$ (Crawford et al. 2006b). The penguin's peak breeding season in autumn/winter coincides with the arrival in May to June of young-of-year fish from the nursery grounds located north of the penguin colonies, en route to join the shoals of adult fish (see Fig. 4b). The young fish present inshore in autumn-winter are available to penguins which have restricted foraging ranges and that usually target smaller prey items than gannets when breeding. African penguins and Cape gannets avoid direct competition for resources through having adjusted the timing of their respective reproductive seasons relative to annual prey migration patterns and their abilities to exploit these resources at different periods. 
(a) Cape gannet's peak breeding season

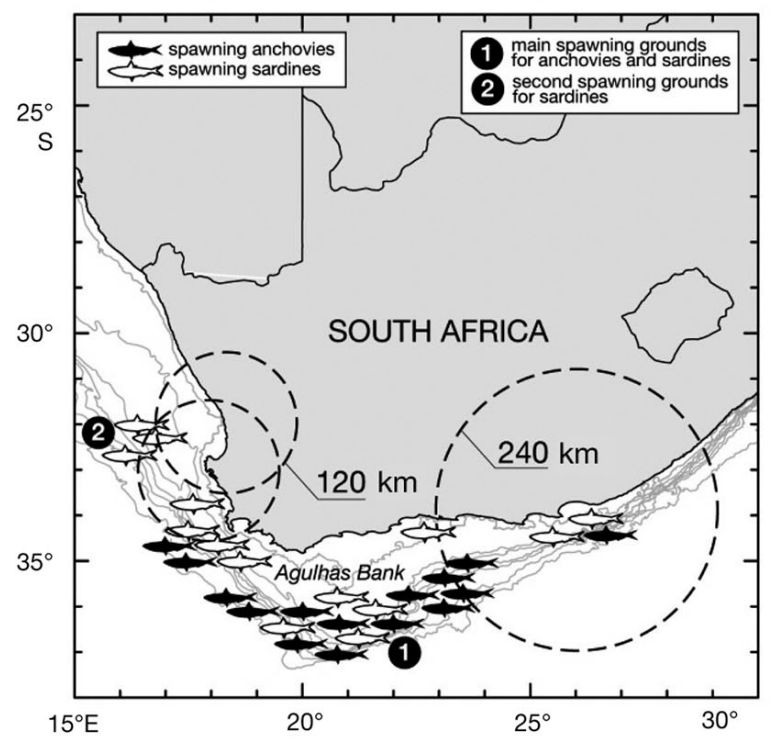

(b) African penguin's peak breeding season

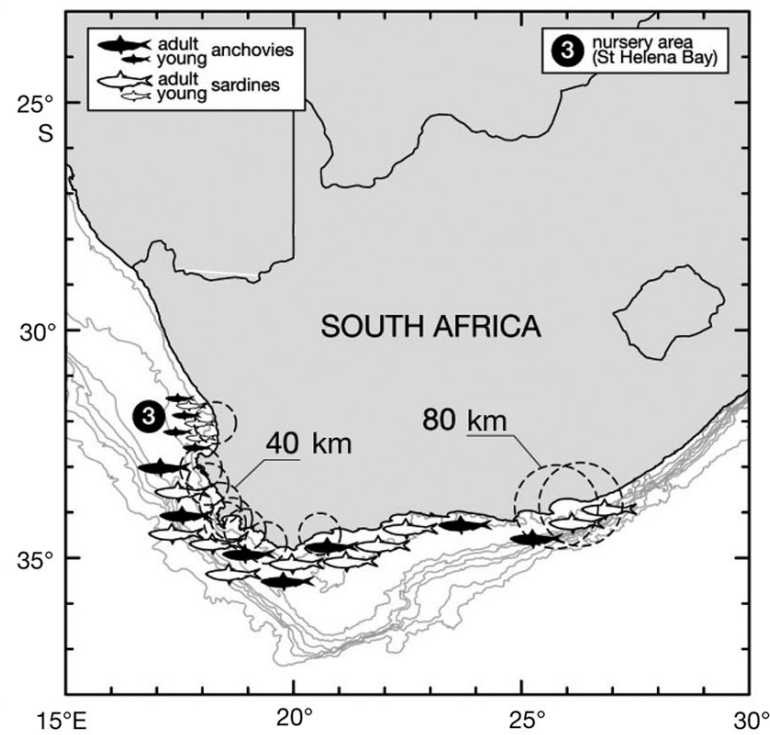

Fig. 4. Approximate distribution of sardines (in white) and anchovies (in black) — according to their life cycle (e.g. spawning in late spring, young-of-the-year growing in autumn) - during the peak breeding season of (a) Cape gannets Morus capensis (around November) and (b) African penguins Spheniscus demersus (around May). Circles: seabird foraging ranges

\section{CONCLUSIONS}

The response of seabirds to common prey fluctuations may differ. Proximate causes that may explain different responses are related to the unique adaptation/behaviour of each seabird species, e.g. mode of locomotion, foraging range, foraging behaviour, dietary plasticity and pattern of moult. The speciesspecific characteristics of the 3 seabirds highlight abilities and constraints that allow these species to partition resources either in time (e.g. timing of the breeding season) or space (e.g. vertical space via contrasting hunting techniques), and with different degrees of dependency on the resource.

This study raises questions related to the foraging ecology of the different seabirds that will need to be further investigated, notably Cape cormorant diet and foraging trip duration, as well as more direct studies of all 3 species' foraging distributions and potential feeding commensalism or interference.

Ecosystem-based management of fisheries is important to any fished ecosystem, and studies such as this one that relate numerical responses of predators to prey indices provide guidance on how to integrate predator needs into fisheries management (Cury et al. 2011). South African fisheries are now expected fully to integrate seabird requirements in terms of food when defining fishing quotas, especially for the 'Endangered' African penguin and the 'Vulnerable' Cape gannet (www.iucnredlist.org).
Acknowledgements. We are grateful to E. Edeline and T. Rouyer for their help throughout this study. We thank the staff of Ocean and Coasts (previously Marine and Coastal Management, Cape Town, South Africa), who were involved in the seabird monitoring program, and those who gathered the fishing data. Finally we are thankful to the Norwegian Research Council for supporting J.M.D. (MICO project under the 'Fribio' programme), to Marie Curie actions under FP6 (MEST-CT-2005-020932) for supporting P.S.S. at the CEES-MCO training site and to South Africa's National Research Foundation for supporting R.J.M.C. We also thank our institutions for supporting our research.

\section{LITERATURE CITED}

Abrams RW, Griffiths AM (1981) Ecological structure of the pelagic seabird community in the Benguela Current region. Mar Ecol Prog Ser 5:269-277

Ainley DG, Anderson DW, Kelly PR (1981) Feeding ecology of marine cormorants in southwestern North America. Condor 83:120-131

Ainley DG, Ford RG, Brown ED, Suryan RM, Irons DB (2003) Prey resources, competition, and geographic structure of kittiwake colonies in Prince William Sound. Ecology 84: 709-723

Alley TR (1982) Competition theory, evolution, and the concept of an ecological niche. Acta Biotheor 31:165-179

Bakun A (1990) Global climate change and intensification of coastal ocean upwelling. Science 247:198-201

Bakun A, Weeks SJ (2004) Greenhouse gas buildup sardine submarine eruptions and the possibility of abrupt degradation of intense marine upwelling ecosystems. Ecol Lett 7:1015-1023

Barrett RT, Krasnov YV (1996) Recent responses to changes in stocks of prey species by seabirds breeding in the southern Barents Sea. ICES J Mar Sci 53:713-722 
Boulinier T, Lemel JY (1996) Spatial and temporal variations of factors affecting breeding habitat quality in colonial birds: some consequences for dispersal and habitat selection. Acta Oecol 17:531-552

Camphuysen K, Webb A (1999) Multi-species feeding associations in North Sea. Ardea 87:177-198

Carscadden JE, Montevecchi WA, Daroven GK, Nakashima BS (2002) Trophic relationships among capelin (Mallotus villosus) and seabirds in a changing ecosystem. ICES J Mar Sci 59:1029-1033

Coetzee JC, van der Lingen CD, Hutchings L, Fairweather TP (2008) Has the fishery contributed to a major shift in the distribution of South African sardine? ICES J Mar Sci 65:1676-1688

> Crawford RJM (1980) Seasonal patterns in South Africa's Western Cape purse-seine fishery. J Fish Biol 16:649-664

> Crawford RJM (1998) Responses of African penguins to regime changes of sardine and anchovy in the Benguela system. S Afr J Mar Sci 19:355-364

> Crawford RJM, Dyer BM (1995) Responses by four seabird species to a fluctuating availability of Cape anchovy Engraulis capensis off South Africa. Ibis 137:329-339

> Crawford RJM, Williams AJ, Randall RM, Randall BM, Berruti A, Ross GJB (1990) Recent population trends of jackass penguins Spheniscus demersus off southern Africa. Biol Conserv 52:229-243

> Crawford RJM, Allwright DM, Heÿl CW (1992) High mortality of Cape cormorants (Phalacrocorax capensis) off western South Africa in 1991 caused by Pasteurella multocida. Colon Waterbirds 15:236-238

Crawford RJM, Barham PJ, Undehill LG, Shannon LJ and others (2006a) The influence of food availability on breeding success of African penguins Spheniscus demersus at Robben Island South Africa. Biol Conserv 132: 119-125

Crawford RJM, Hemming M, Kemper J, Klages NTW and others (2006b) Molt of the African penguin Spheniscus demersus in relation to its breeding season and food availability. Acta Zool Sin 52(Suppl):444-447

> Crawford RJM, Dundee BL, Dyer BM, Klages NTW, Meyer MA, Upfold L (2007a) Trends in numbers of Cape gannets (Morus capensis) 1956/1957-2005/2006 with a consideration of the influence of food and other factors. ICES J Mar Sci 64:570-576

> Crawford RJM, Dyer BM, Kemper J, Simmons RE, Upfold L (2007b) Trends in numbers of Cape cormorants (Phalocrocorax capensis) over a 50-year period, 1956-57 to 2006-07. Emu 107:253-261

Crawford RJM, Sabarros PS, Fairweather T, Underhill LG, Wolfaardt AC (2008) Implications for seabirds off South Africa of a long-term change in the distribution of sardine. Afr J Mar Sci 30:177-184

> Croxall JP, Reid K, Prince PA (1999) Diet, provisioning and productivity responses of marine predators to differences in availability of Antarctic krill. Mar Ecol Prog Ser 177: 115-131

Cury P, Bakun A, Crawford RJM, Jarre A, Quinones RA, Shannon LJ, Verheye HM (2000) Small pelagics in upwelling systems: patterns of interaction and structural changes in 'wasp-waist' ecosystems. ICES J Mar Sci 57: 603-618

Cury PM, Shin YJ, Planque B, Durant JM and others (2008) Ecosystem oceanography for global change in fisheries. Trends Ecol Evol 23:338-346

Cury PM, Boyd IL, Bonhommeau S, Anker-Nilssen T and others (2011) Global seabird response to forage fish depletion - one-third for the birds. Science 334:1703-1706 > Danchin E, Cam E (2002) Can non-breeding be a cost of breeding dispersal? Behav Ecol Sociobiol 51:153-163

> Dittmann T, Zinsmeister D, Becker PH (2005) Dispersal decisions: common terns Sterna hirundo choose between colonies during prospecting. Anim Behav 70:13-20

> Duffy DC (1989) Seabird foraging aggregations: a comparison of two southern upwellings. Colon Waterbirds 12: 164-175

Durant JM, Anker-Nilssen T, Stenseth NC (2003) Trophic interactions under climate fluctuations: the Atlantic puffin as an example. Proc R Sec Lond B Biol Sci 270: 1461-1466

> Durant JM, Hjermann DØ, Frederiksen M, Charassin JB and others (2009) Pros and cons of using seabirds as ecological indicators. Clim Res 39:115-129

> Durant JM, Crawford RJM, Wolfaardt AC, Agenbag K, Visagie J, Upfold L, Stenseth NC (2010) Influence of feeding conditions on breeding of African penguins importance of adequate local food supplies. Mar Ecol Prog Ser 420:263-271

- Evans PGH (1982) Associations between seabirds and cetaceans: a review. Mammal Rev 12:187-206

> Fairweather TP, van der Lingen CD, Booth AJ, Drapeau L, van der Westhuizen JJ (2006) Indicators of sustainable fishing for South African sardine Sardinops sagax and anchovy Engraulis encrasicolus. Afr J Mar Sci 28:661-680

Furness RW, Barrett RT (1991) Ecological responses of seabirds to reductions in fish stocks in north Norway and Shetland. Acta XXth Congresus Internationalis Ornithologici 4:2241-2245

> Grémillet D, Argentin G, Schulte B, Culik BM (1998) Flexible foraging techniques in breeding cormorants Phalacrocorax carbo and shags Phalacrocorax aristotelis: Benthic or pelagic feeding? Ibis 140:113-119

Grémillet D, Kuntz G, Delbart F, Mellet M and others (2004) Linking the foraging performance of a marine predator to local prey abundance. Funct Ecol 18:793-801

Hanski I, Gaggiotti OE (eds) (2004) Ecology, genetics and evolution of metapopulations. Elsevier Academic Press, San Diego, CA

Hockey P, Dean WR, Ryan PG (eds) (2005) Roberts birds of southern Africa. John Voelker Bird Book Fund, Cape Town

Johnson AR, Wiens JA, Milne BT, Crist TO (2006) Seabird predation by white shark Carcharodon carcharias and Cape fur seal Arctocephalus pusillus pusillus at Dyer Island. S Afr J Wildl Res 36(1):23-32

- Kato A, Watanuki Y, Naito Y (2001) Foraging and breeding performance of Japanese cormorants in relation to prey type. Ecol Res 16:745-758

Le Bohec C, Durant JM, Gauthier-Clerc M, Stenseth NC and others (2008) King penguin population threatened by Southern Ocean warming. Proc Natl Acad Sci USA 105: 2493-2497

Le Corre M, Jaquemet S (2005) Assessment of seabird community of the Mozambique Channel and its potential use as indicator of tuna abundance. Estuar Coast Shelf Sci 63:421-428

> Lewis S, Grémillet D, Daunt F, Ryan PG, Crawford RJM, Wanless S (2006) Using behavioural and state variables to identify proximate causes of population change in a seabird. Oecologia 147:606-614

R Development Core Team (2007) R: a language and envi- 
ronment for statistical computing. R Foundation for Statistical Computing, Vienna

Roy C, van der Lingen CD, Coetzee JC, Lutjeharms JRE (2007) Abrupt environmental shift associated with changes in the distribution of Cape anchovy Engraulis encrasicolus spawners in the southern Benguela. Afr J Mar Sci 29:309-319

Sandvik H, Erikstad KE (2008) Seabird life histories and climatic fluctuations: a phylogenetic-comparative time series analysis of North Atlantic seabirds. Ecography 31: 73-83

Underhill LG, Crawford RJM, Wolfaardt AC, Whittington PA, Dyer BM, Leshoro TM, Ruthenberg M (2006) Regionally coherent trends in colonies of African penguins

Editorial responsibility: Janet Ley,

St. Petersburg, Florida, USA
Spheniscus demersus in the Western Cape South Africa 1987-2005. Afr J Mar Sci 28:697-704

van der Lingen CD, Coetzee JC, Demarcq H, Drapeau L, Fairweather TP, Hutchings L (2005) An eastward shift in the distribution of southern Benguela sardine. Globec Int Newsl 11:17-22

> Vleck CM, Vleck D (2002) Physiological condition and reproductive consequences in Adelie penguins. Integr Comp Biol 42:76-83

Waller LJ, Underhill LG (2007) Management of avian cholera Pasteurella multocida outbreaks on Dyer Island, South Africa, 2002-2005. Afr J Mar Sci 29:105-111

Wood SN (2006) Generalized additive models: an introduction with R. Chapman \& Hall, New York, NY

Submitted: February 23, 2010; Accepted: July 30, 2012

Proofs received from author(s): October 24, 2012 